\title{
TRADUÇÃO DA PRIMEIRA SÁTIRA DE JUVENAL EM HEXÂMETROS PORTUGUESES
}

\author{
Érico Nogueira* \\ Recebido em: 18/02/2019 \\ Aprovado em: 16/4/2019 \\ INTRODUÇÃo \\ primeira sátira de Juvenal, como tantos outros poemas
exordiais da literatura latina, é ao mesmo tempo apologia e
recusa - isto é, neste caso, apologia da sátira, e recusa \\ de outros gêneros da poesia, em especial a épica. Como o rol de \\ motivos e assuntos de que esse poema trata é deveras extenso (cf. \\ v. 85-86: "tudo o que fazem os homens - promessa, ira, medo, \\ prazer, / contentos, canseiras - é forragem do nosso livrinho”), e \\ o tratamento mesmo é sinuoso, cheio de repetições e vaivéns, segue \\ uma lista completa e detalhada que certamente ajudará o leitor a \\ compreender melhor o que for ler:
}

* Professor de Língua e Literatura Latina, Departamento de Letras, Escola de Filosofia, Letras e Ciências Humanas, Universidade Federal de São Paulo. nogueiraerico@gmail.com

1-18. Por que escrever? Recusa de outros gêneros em favor da sátira.

19-21 A sátira.

22-51 Temas ou assuntos passíveis de sátira:
a) efeminados;
b) atrizes;
c) novos-ricos;
d) delatores;
e) os que casam por interesse.

52-54 O caráter inofensivo da poesia "mitológica".

55-78 Outros temas ou assuntos passíveis de sátira:

f) o cáften;

g) a nobreza decadente;

h) o falsário; 
i) a mulher que envenena o marido;

j) o corruptor de mulheres casadas;

l) o adolescente adúltero.

79-86 "A indignação faz o verso".

87-146 Terceiro rol de temas passíveis de sátira:

m) o jogo;

n) a relação entre patrão e cliente.

147-161 "Todo vício chegou ao cúmulo".

162-164 Novamente o caráter inofensivo da poesia "mitológica".

165-171 Conclusão.

Finalmente, é preciso observar que nossa tradução buscou seguir bem de perto o original latino, e, pois, reelabora ou tenta reelaborar em português a elocução, o léxico, a ordem mesma dos vocábulos na sentença - e, na medida em que o permitam as diferenças fonológicas entre o latim e o português, também o metro do original..$^{1}$ Donde a variação rítmica e silábica do nosso verso, que, embora de andamento preponderantemente dactílico, não evita o espondeu - que sugere por ditongos, sinéreses e afins -, e admite anacruse (embora não obrigatória) se o fim do verso anterior for agudo.

Quanto às traduções poéticas da primeira sátira de Juvenal em português, é preciso mencionar as decassilábicas de Francisco Antônio Martins Bastos e Antônio de Sousa da Silva Costa Lobo, ${ }^{3}$ ambas do século XIX, e a recentíssima tradução hexamétrica de Rafael Cavalcanti do $\mathrm{Carmo}^{4}$ - da qual a exatidão semântica e a qualidade propriamente poética, porém, parecem ter sido prejudicadas pelas injunções do ritmo.

\footnotetext{
${ }^{1}$ Para a história do hexâmetro em português, cf. Oliva Neto e Nogueira (2013). Sobre os distintos métodos de ler, escandir e reproduzir medidas latinas em português, veja-se Nogueira (2018). Notese, finalmente, que chamamos ao verso vernáculo usado nesta nossa tradução de Juvenal "hexâmetro português" por mera convenção - isto é, cientes de que, em última instância, uma língua de silabação qualitativa, como o português, não logra reproduzir um verso fundado em silabação quantitativa, como é o hexâmetro latino.

${ }^{2}$ Cf. As satyras de Decio Junio Juvenal, principe dos poetas satyricos (trad. Francisco Antonio Martins Bastos, 1839).

${ }^{3}$ Cf. Satiras de Juvenal trasladadas em verso portuguez (trad. Antonio de S. S. Costa Lobo, 1878-1881).

${ }^{4}$ Cf. Carmo (2018).
} 


\section{Texto e Tradução}

O texto que traduzimos e estampamos a seguir é o de Susanna Morton Braund (Juvenal and Persius. London / Cambridge-MA: Loeb, 2004). As notas que acompanham a tradução foram reduzidas às que julgamos indispensáveis para a compreensão algo mais cômoda e direta do original, sem a pretensão de entrar em questões delicadas de exegese linguística ou literária.

\footnotetext{
Semper ego auditor tantum? numquamne reponam vexatus totiens rauci Theseide Cordi? impune ergo mihi recitaverit ille togatas, hic elegos? impune diem consumpserit ingens Telephus aut summi plena iam margine libri scriptus et in tergo necdum finitus Orestes? nota magis nulli domus est sua quam mihi lucus Martis et Aeoliis vicinum rupibus antrum Vulcani; quid agant venti, quas torqueat umbras Aeacus, unde alius furtivae devehat aurum pelliculae, quantas iaculetur Monychus ornos, Frontonis platani convolsaque marmora clamant semper et adsiduo ruptae lectore columnae. exspectes eadem a summo minimoque poeta. et nos ergo manum ferulae subduximus, et nos consilium dedimus Sullae, privatus ut altum dormiret. stulta est clementia, cum tot ubique vatibus occurras, periturae parcere chartae. cur tamen hoc potius libeat decurrere campo, per quem magnus equos Auruncae flexit alumnus, si vacat ac placidi rationem admittitis, edam. Cum tener uxorem ducat spado, Mevia Tuscum figat aprum et nuda teneat venabula mamma, patricios omnis opibus cum provocet unus quo tondente gravis iuveni mihi barba sonabat, cum pars Niliacae plebis, cum verna Canopi Crispinus Tyrias umero revocante lacernas ventilet aestivum digitis sudantibus aurum nec sufferre queat maioris pondera gemmae,
}

Sempre eu só de ouvinte? Jamais irei descontar, vexado amiúde pela Teseida de Cordo ${ }^{5}$ roufenho? Ora, impune me vai recitar, - um, tragédias togadas, o outro, elegias? Gastar vai impune o meu dia um enorme

5 Télefo ${ }^{6}$ ou, com a margem extrema do livro já cheia, um escrito no verso também e ainda não terminado Orestes ${ }^{7}$ ? Mais conhecida não é de ninguém sua casa que a mim o bosque de Marte e a gruta confim às escarpas eólias de Vulcano: e o que fazem os ventos, que sombras tortura

10 Éaco, de onde o fulano traz o ouro da surripiada pelezinha, quantos ulmeiros Monico arremessa ${ }^{8}$ - gritam-no os plátanos de Frontão ${ }^{9}$ e os seus mármores moídos continuamente e as colunas roídas do instante leitor. Esperarás o mesmo do máximo e o mínimo poeta.

15 Nós também desviamos da férula a mão, nós também conselho demos a Sila - ora, que, reformado, pesado fosse dormir. ${ }^{10}$ É clemência estultíssima, se em toda a parte topas com poetas, poupar um papel destinado a morrer. Por que, contudo, prefiro correr o mesmíssimo campo

20 pelo qual o grão filho de Aurunca guiou seus cavalos, ${ }^{11}$ se calhar e folgardes de ouvir-me as razões, dir-vos-ei. Quando um molíssimo eunuco se casa, Mévia ${ }^{12}$ um etrusco porco transfixa e segura os venábulos com a teta de fora, quando os patrícios todos em bens desafia sozinho

25 quem me afeitava em rapaz a barba que hirsuta estalava, quando o restolho da plebe do Nilo - o Crispim de Canopo, verna - ao ombro jogando a sua capa purpúrea faz ventilar o ouro estivo de anéis em seus dedos suados sem poder suportar o peso de gema maior,

\footnotetext{
${ }^{5}$ Poeta desconhecido, autor de um poema épico sobre as gestas de Teseu.

${ }^{6}$ Isto é, uma tragédia.

${ }^{7}$ Também uma tragédia.

${ }^{8}$ Todos os episódios referidos nesta sequência se referem à história dos argonautas, tal e como a podemos ler nas Argonáuticas de Valério Flaco. Trata-se, pois, de crítica e recusa da épica "mitológica" ou "ficcional".

${ }^{9}$ Ricaço em cuja mansão se davam leituras de poesia como a criticada nesta sátira.

${ }^{10}$ Referência à prática da declamação escolar, isto é, aos exercícios de retórica tão comuns na escola romana do período. Lúcio Cornélio Sila (138 - 78 a.C.) foi um general e ditador romano.

${ }^{11} \mathrm{O}$ grão filho de Aurunca (cidade da Campânia) referido no passo não é outro senão Caio Lucílio, o inventor - ou reinventor - da poesia satírica.

${ }^{12}$ Atriz desconhecida.
} 
difficile est saturam non scribere. nam quis iniquae tam patiens urbis, tam ferreus, ut teneat se, causidici nova cum veniat lectica Mathonis plena ipso, post hunc magni delator amici et cito rapturus de nobilitate comesa quod superest, quem Massa timet, quem munere palpat 35 Carus et a trepido Thymele summissa Latino; cum te summoveant qui testamenta merentur noctibus, in caelum quos evehit optima summi nunc via processus, vetulae vesica beatae? unciolam Proculeius habet, sed Gillo deuncem, partes quisque suas ad mensuram inguinis heres. accipiat sane mercedem sanguinis et sic palleat ut nudis pressit qui calcibus anguem aut Lugudunensem rhetor dicturus ad aram. quid referam quanta siccum iecur ardeat ira, cum populum gregibus comitum premit hic spoliator pupilli prostantis et hic damnatus inani iudicio? quid enim salvis infamia nummis? exul ab octava Marius bibit et fruitur dis iratis, at tu victrix, provincia, ploras. haec ego non credam Venusina digna lucerna? haec ego non agitem? sed quid magis? Heracleas aut Diomedeas aut mugitum labyrinthi et mare percussum puero fabrumque volantem, cum leno accipiat moechi bona, si capiendi ius nullum uxori, doctus spectare lacunar, doctus et ad calicem vigilanti stertere naso; cum fas esse putet curam sperare cohortis qui bona donavit praesepibus et caret omni maiorum censu, dum pervolat axe citato Flaminiam puer Automedon? nam lora tenebat ipse, lacernatae cum se iactaret amicae. nonne libet medio ceras implere capaces quadrivio, cum iam sexta cervice feratur hinc atque inde patens ac nuda paene cathedra et multum referens de Maecenate supino signator falsi, qui se lautum atque beatum exiguis tabulis et gemma fecerit uda? occurrit matrona potens, quae molle Calenum
30 difícil é sátiras não escrever. Ora, quem, ante a iníqua Urbe, é tão paciente, tão férreo, que se contenha quando passa a nova liteira do rábula Matão cheia do próprio, após ele o alcaguete de mui grande amigo, e muito em breve raptor da nobreza dilapidadíssima - do que inda resta -, que até Massa teme, que Caro com dons afaga, ${ }^{13}$ qual Tímele enviada em missão por um trêmulo Latino; ${ }^{14}$ quando te enxotam os que de testamentos se beneficiam noturnamente, aos quais leva ao céu hoje a via melhor da suma escalada - a boceta de alguma opulenta velhota?

40 Tem Proculeio uma oncinha, Gilão, por seu turno, tem onze, cada herdeiro a fração proporcional à piroca.

Ambos, claro, recebam o salário do sangue e assim empalideçam qual quem pisa em serpe com os pés descalçados ou o orador que vai discursar ante o altar de Lião. ${ }^{15}$

45 Por que revelar quanta ira fervilha em meu fígado seco, quando, com a malta de cúmplices, pisa no povo o espoliante do órfão que faz de michê - um condenado por uma sentença sem efeito? Ora, a infâmia o que importa, com as moedas a salvo? Mário ${ }^{16}$ exilado a partir das catorze bebe e desfruta

50 a ira dos deuses, mas tu, vencedora província, tu choras. Tais não crerei coisas dignas da horacianíssima ${ }^{17}$ lâmpada? Tais não achacarei? Mas o que, se não isso? As hercúleas ou diomédicas ou o mugido no labirinto ou o mar fendido pelo mancebo e o artesão voador, ${ }^{18}$

55 quando um rufião os regalos sequestra do amante à mulher, dos quais a lei mesma a priva - tão douto em olhar para o teto, douto em roncar junto à taça com o vígil nariz? Quando lícito julga esperar um comando de coorte quem doou os seus bens aos estábulos falto de todo

60 patrimônio ancestral, ao voar, rodas em disparada, pela Flamínia - novo Automedonte? Ora, as rédeas sustinha ele próprio, ao mostrar-se para a encapotada amiguinha. Aí não é lícito encher anchas tábuas de cera no meio da encruzilhada, quando são seis as cabeças que levam

65 lá e ali, exposto em seminua cadeira e recordando muito o reclinado Mecenas, ${ }^{19}$ um falsário que se tornou refinado e opulento com diminutas tabuinhas e mais um sinete molhado? Vem poderosa matrona que, o relaxante caleno ${ }^{20}$

\footnotetext{
${ }^{13}$ Bébio Massa e Métio Caro foram dois alcaguetes durante o principado de Domiciano.

${ }^{14}$ Latino e Tímele são atores.

${ }^{15}$ Referência aos castigos infligidos aos perdedores nos torneios de oratória em Lião.

${ }^{16}$ Mário Prisco, exilado por extorsão.

${ }^{17}$ Em latim, literalmente, "Venusina”, isto é, venusina, de Venúsia, pátria de Horácio. Daî "horacianíssima" em português, com cujo superlativo pretendemos imitar a elocução enfática e incisiva de Juvenal.

${ }^{18}$ Neste passo se faz referência a assuntos próprios da épica.

${ }^{19}$ Caio Clínio Mecenas (70 - 8 a.C.), célebre patrono das artes durante o principado de Augusto.

${ }^{20}$ Vinho de altíssima qualidade proveniente da Campânia.
} 
porrectura viro miscet sitiente rubetam instituitque rudes melior Lucusta propinquas per famam et populum nigros efferre maritos. aude aliquid brevibus Gyaris et carcere dignum, si vis esse aliquid. probitas laudatur et alget; criminibus debent hortos, praetoria, mensas, argentum vetus et stantem extra pocula caprum. quem patitur dormire nurus corruptor avarae, quem sponsae turpes et praetextatus adulter? si natura negat, facit indignatio versum qualemcumque potest, quales ego vel Cluvienus. ex quo Deucalion nimbis tollentibus aequor navigio montem ascendit sortesque poposcit paulatimque anima calverunt mollia saxa et maribus nudas ostendit Pyrrha puellas, quidquid agunt homines, votum, timor, ira, voluptas, gaudia, discursus, nostri farrago libellist. et quando uberior vitiorum copia? quando maior avaritiae patuit sinus? alea quando hos animos? neque enim loculis comitantibus itur ad casum tabulae, posita sed luditur arca. proelia quanta illic dispensatore videbis armigero! simplexne furor sestertia centum perdere et horrenti tunicam non reddere servo? quis totidem erexit villas, quis fercula septem secreto cenavit avus? nunc sportula primo limine parva sedet turbae rapienda togatae. ille tamen faciem prius inspicit et trepidat ne suppositus venias ac falso nomine poscas: agnitus accipies. iubet a praecone vocari ipsos Troiugenas, nam vexant limen et ipsi nobiscum. "da praetori, da deinde tribuno." sed libertinus prior est. "prior" inquit "ego adsum. cur timeam dubitemve locum defendere, quamuis natus ad Euphraten, molles quod in aure fenestrae arguerint, licet ipse negem? sed quinque tabernae quadringenta parant. quid confert purpura maior optandum, si Laurenti custodit in agro conductas Corvinus ovis, ego possideo plus Pallante et Licinis?” exspectent ergo tribuni,
70 indo ao esposo servir, põe-lhe sumo sedento de sapo e ensinou - melhorada Locusta - as rudes vizinhas entre o escândalo e a turba a enterrar gangrenados maridos. Ousa algo digno da Gíara estreita ${ }^{21}$ e, enfim, da prisão, se queres ser algo. A honradez é louvada, mas fica no gelo;

75 pois aos crime se devem jardins, palácios, banquetes, prata antiga e púcaros donde releva um cabrão. Quem da cúpida nora o corruptor dormir deixa, quem as torpes esposas e o adúltero adolescente? Se a natureza falece, a indignação faz o verso

80 como pode - quais posso eu ou então Cluvieno. ${ }^{22}$ Desde que Deucalião, o mar subindo com as chuvas, de navio escalou a montanha e um oráculo pediu e aos poucos amoleceram as pedras acesas de vida e também aos varões mostrou Pirra as nuas moçoilas, ${ }^{23}$

85 tudo o que fazem os homens - promessa, ira, medo, prazer, contentos, canseiras - é forragem do nosso livrinho. Ora, quando mais rica cópia de vícios, quando mais a ambição escancarou o seio, e o jogo foi quando tão animado? Pois não se vai em companhia da bolsa

90 para o acaso da mesa, mas joga-se uma arca em apostas. Quantas batalhas ali não verás diante do armígero crupiê! É loucura singela perder cem mil sestércios e ao escravo tremente não dar uma túnica? Qual avô ergueu tantas vilas, qual sete bandejas

95 solitariamente jantou? Hoje a minicestinha ${ }^{24}$ jaz no primeiro umbral para o rapto da turba togada. Ele, no entanto, inspeciona primeiro e receia que acaso venhas em pele alheia e sob nome falso demandes: reconhecido, recebes. Ordena ao pregoeiro chamar

100 os próprios troianos, ${ }^{25}$ que os próprios junto conosco também sitiam o umbral. "Dá ao pretor. Em seguida, dá ao tribuno". Mas o liberto é o primeiro. "Primeiro", diz ele, "eu cheguei. Por que hei de temer ou recear defender este posto, apesar de nascido no Eufrates - o que os moles furos na orelha

105 provariam, se eu negasse? Porém, minhas cinco lojinhas dão quatrocentos mil: dá a púrpura senatorial o que se deseja, uma vez que Corvino ${ }^{26}$ no campo laurente guarda ovelhas de soldada, enquanto eu tenho mais do que Palante e os Licínios?”. Esperem, pois, os tribunos,

\footnotetext{
${ }^{21}$ Ilha no mar Egeu.

22 Poeta desconhecido, provavelmente um amador.

${ }^{23}$ Resumo da história de Deucalião e Pirra (cf. Ovídio, Metamorfoses, I, 253-416).

${ }^{24} \mathrm{Na}$ qual os patronos costumavam dar dinheiro aos seus clientes.

${ }^{25}$ Isto é, as mais nobres famílias romanas, supostamente descendentes dos troianos, como nos narra

a Eneida de Virgílio.

${ }^{26}$ Um nobre.
} 
vincant divitiae, sacro ne cedat honori nuper in hanc urbem pedibus qui venerat albis, quandoquidem inter nos sanctissima divitiarum maiestas. etsi funesta Pecunia templo nondum habitat, nullas nummorum ereximus aras, ut colitur Pax atque Fides, Victoria, Virtus quaeque salutato crepitat Concordia nido. sed cum summus honor finito computet anno, sportula quid referat, quantum rationibus addat, quid facient comites quibus hinc toga, calceus hinc est et panis fumusque domi? densissima centum quadrantes lectica petit, sequiturque maritum languida vel praegnas et circumducitur uxor. hic petit absenti nota iam callidus arte ostendens vacuam et clausam pro coniuge sellam. "Galla mea est" inquit, "citius dimitte. moraris? profer, Galla, caput. noli vexare, quiescet." Ipse dies pulchro distinguitur ordine rerum: sportula, deinde forum iurisque peritus Apollo atque triumphales, inter quas ausus habere nescio quis titulos Aegyptius atque Arabarches, cuius ad effigiem non tantum meiere fas est. vestibulis abeunt veteres lassique clientes votaque deponunt, quamquam longissima cenae spes homini; caulis miseris atque ignis emendus. optima silvarum interea pelagique vorabit rex horum vacuisque toris tantum ipse iacebit. nam de tot pulchris et latis orbibus et tam antiquis una comedunt patrimonia mensa. nullus iam parasitus erit. sed quis ferat istas luxuriae sordes? quanta est gula quae sibi totos ponit apros, animal propter convivia natum! poena tamen praesens, cum tu deponis amictus turgidus et crudum pavonem in balnea portas. hinc subitae mortes atque intestata senectus. it nova nec tristis per cunctas fabula cenas; ducitur iratis plaudendum funus amicis. Nil erit ulterius quod nostris moribus addat posteritas, eadem facient cupientque minores, omne in praecipiti vitium stetit. utere velis, totos pande sinus. dices hic forsitan "unde ingenium par materiae? unde illa priorum scribendi quodcumque animo flagrante liberet simplicitas? "cuius non audeo dicere nomen? quid refert dictis ignoscat Mucius an non?” pone Tigellinum, taeda lucebis in illa qua stantes ardent qui fixo gutture fumant,
110 vençam as riquezas, e o passo não ceda ao cargo sagrado quem há pouco chegava a esta urbe com os pés alvacentos, ${ }^{27}$ já que entre nós é santa santíssima a majestade das riquezas, embora a funesta Pecúnia um templo inda não habite, e altares nenhuns erigimos às moedas,

115 como a Paz se cultua, e a Confiança, a Vitória, a Virtude, e a Concórdia que arrulha aquando o seu ninho é saudado. ${ }^{28}$ Mas, quando o máximo cargo o balanço faz ao fim do ano do que rende a cestinha, de quanto acrescenta ao seu saldo, que farão os clientes que dela têm toga e calçado

120 mais o pão e a lenha da casa? Bastíssimas liteiras pedem os cem quadrantes, ${ }^{29}$ e vai atrás do marido lânguida ou grávida esposa que levam ali e acolá. Um, habilíssimo na arte manjada, pede a uma ausente, apontando, em vez da mulher, selim vácuo e fechado.

125 "Eis minha Gala", diz, "anda logo. Por que te demoras? Mostra, Gala, o teu rosto". "Não na incomodes: dormiu". O próprio dia é marcado por linda sequência de eventos: cesta, depois o fórum de Apolo jurisperito e a estatuária triunfal, no meio da qual ousou pôr

130 seus títulos um não sei qual egípcio ou alfandegário, em cuja efígie não somente mijar lícito é.

Deixaram os vestíbulos os velhos e fatigados clientes e depõem os seus votos, conquanto longuíssima no homem seja a esperança de ceia: e almeirão compra o pobre, mais fogo.

135 Entretanto, o melhor das florestas e mar tragará o grão-senhor deles, sozinho deitado em leitos vazios. Com efeito, entre távolas tão belas e amplas e tão antigas, um patrimônio eles comem em mesa de um só. Nenhum parasita mais haverá. Mas quem aguenta esta

140 sordidez luxuosa? Que gula tamanha se serve porcos inteiros, um bicho nascido para as festanças? Todavia, o castigo é instantâneo, pois tiras o manto empanzinado, e indigesto pavão levas tu ao banheiro. Daí mortes súbitas e uma velhice sem testamento.

145 Corre a recente e não triste notícia por todos os jantares; sai o funeral, que os amigos furiosos terão de aplaudir. Nada além disso o futuro terá que acrescente aos costumes nossos, e o mesmo farão, quererão os da nossa prosápia: todo vício chegou ao cúmulo. Solta os panos,

150 todas as velas se enfunem. Dirás, porventura, "Mas onde há um engenho à altura do assunto? Onde aquela ancestral franqueza de escrever o que quer que ao espírito em brasa bem parecesse?". O nome de quem não ouso dizer? Que me importa se Múcio $^{30}$ perdoa-me a língua ou não?

155 "Pinta Tigelino, ${ }^{31}$ e hás de brilhar na tal tocha onde ardem de pé e fumegam os de goela amarrada,

\footnotetext{
${ }^{27}$ Característica física do escravo estrangeiro.

${ }^{28}$ Porque as cegonhas faziam ninhos - e, pois, arrulhavam - no templo da Concórdia.

${ }^{29}$ Moeda de pouco valor.

${ }^{30}$ Públio Múcio Cévola, político eminente atacado por Lucílio.

${ }^{31}$ Caio Ofônio Tigelino, um protegido de Nero.
} 
$* * *$

et latum media sulcum deducit harena." qui dedit ergo tribus patruis aconita, vehatur pensilibus plumis atque illinc despiciat nos? "cum veniet contra, digito compesce labellum: accusator erit qui verbum dixerit 'hic est.' securus licet Aenean Rutulumque ferocem committas, nulli gravis est percussus Achilles aut multum quaesitus Hylas urnamque secutus: ense velut stricto quotiens Lucilius ardens infremuit, rubet auditor cui frigida mens est criminibus, tacita sudant praecordia culpa. inde ira et lacrimae. tecum prius ergo voluta haec animo ante tubas: galeatum sero duelli paenitet." experiar quid concedatur in illos quorum Flaminia tegitur cinis atque Latina.
$* * *$

e a carcaça abre um largo sulco no meio do chão". Logo, o que acônito deu aos três tios, será carregado em almofadas de pluma, e de lá vai olhar-nos soberbo?

160 "Quando cruzar contigo, coloca o dedo na boca: delator há de ser quem a frase soltar 'Sim, é ele!'. Sem perigo porás Eneias e o rútulo fero em combate, a ninguém agrava um Aquiles furado ou Hilas procuradíssimo após ir atrás do seu cântaro: ${ }^{32}$

165 sempre que o ardido Lucílio, porém, qual se a espada empunhara, brame, enrubesce o ouvinte que tem a consciência gelada dos seus crimes, e suam as entranhas da culpa silente. Donde ira e lágrimas. Volve-o contigo primeiro no espírito antes de soar a trombeta: o armado da luta arrepende-se

170 tarde". Vou ver o que se me concede, pois, contra aqueles cujas cinzas espalham-se sob a Flamínia e a Latina. ${ }^{33}$

\section{REFERÊNCIAS}

CARMO, Rafael Cavalcante do. Difficile est Saturam Bene Vertere: Os Desafios da Tradução Poética e uma Versão Brasileira das Sátiras de Juvenal. 290 f. Tese (Doutorado em Letras) - Programa de Pós-Graduação em Letras, Centro de Ciências Humanas e Naturais, Universidade Federal do Espírito Santo, Vitória, 2018. Disponível em: http://letras.ufes.br/ pt-br/pos-graduacao/PPGL/detalhes-da-tese?id=12155

JUVENAL. As sátiras de Decio Junio Juvenal, principe dos poetas satyricos. Introdução, tradução e notas por Francisco Antonio Martins Bastos. Lisboa: Imprensa de Candido A. da S. Carvalho, 1839.

JUVENAL. Sátiras de Juvenal trasladadas em verso portuguez: Introdução, tradução e notas por Antonio de S. S. Costa Lobo. Lisboa: Imprensa Nacional, 1878-1881.

JUVENAL; PERSIUS. Juvenal and Persius. Edited and translated by Susanna Morton Braund. Cambridge: Harvard University, 2004.

NOGUEIRA, Érico. Medidas latinas em verso português. Cadernos de Tradução, v. 38, n. 3, p. 142-158, set-dez 2018. doi: https://doi.org/10.5007/2175-7968.2018v38n3p142

OLIVA NETO, João Angelo; NOGUEIRA, Érico. O hexâmetro dactílico vernáculo antes de Carlos Alberto Nunes. Scientia Traductionis, n. 13, p. 295-311, jul. 2013. doi: https://doi. org/10.5007/1980-4237.2013n13p295

\footnotetext{
${ }^{32}$ Referência a temas épicos.

${ }^{33}$ Apenas figuras ricas e eminentes eram enterradas nas referidas vias.
} 